\title{
Design of Carbon/Epoxy Composite Drive Shaft for Low Passenger Vehicles
}

\author{
Dhiraj D. Patil ${ }^{1 *}$, Rajaram M. Shinde ${ }^{2}$ and Suresh M. Sawant ${ }^{3}$
}

${ }^{1}$ Automobile Engineering Department, 2,3Mechanical Engineering Department Shivaji University, RIT Rajaramnagar, Islampur, Maharashtra, India

Accepted 01 Sept 2016, Available online 02 Sept 2016, Vol.6, No.5 (Oct 2016)

\begin{abstract}
The drive shaft or propeller shaft is one of the important components in the vehicles. A drive shaft is a rotating shaft that transmits power from the engine to the differential gear of a rear wheel drive vehicles. Generally an alloy steel drive shaft is used in automotive, but now a days this steel drive shaft is replaced by composite material drive shaft. The advanced composite materials such as graphite, carbon, Kevlar and glass with suitable resins are widely used because of their high specific strength and high specific module. Due to replacement of composite material can results in considerable amount of weight reduction as compared to steel shaft. In this study composite shaft is designed successfully and applied to minimize the weight of shaft which is subjected to the constraints such as torque transmission, critical speed and fundamental natural frequency. This work deals with the replacement of conventional steel drive shaft with high strength carbon/epoxy composite drive shaft.
\end{abstract}

Keywords: Driveshaft, Composite driveshaft, Torsional strength, Natural frequency, Weight minimization.

\section{Introduction}

A drive shaft is a device that transmits the rotating force of an engine or a gear box to driving axles and is widely used in machinery including transport machines such as automobiles, ships and aircraft. The driveshaft is used for the transfer of motion from one point to another point and also the shafts which propel are mentioned to as the propeller shaft. The ships and planes are usually associated with the propellers as they are propelled using propeller shaft in water or air. Driveshaft is used for transmitting the rotary motion from the front end to the rear end of the vehicle to move the vehicle forward. The primary connection between front end and the rear end is driveshaft or propeller shaft which makes both the motion and driving the front end in either forward or backward direction (Reimpell \& Stroll,1996),

Generally, when the engine is situated at the opposite end of the vehicle then the driven wheels are connected by using the propeller shaft. Driveshaft consists of one or more tubular shaft linked by constant velocity or flexible joints and the universal joints. The distance between gearbox and the live axle affects the number of tubular pieces and the joints. The four wheel drive vehicles are equipped with the two propeller shaft from which one propeller shaft is used

*Corresponding author: Dhiraj D. Patil to power the front wheels and second propeller shaft is used to power the rear wheels. In this four wheel drive vehicle, the second drive shaft is situated between a transfer gear box and the front axle. Hence, the responsible component for the actual movement of the vehicle when the motion is produced in the engine and therefore it is one of the most important components When the vehicle is in motion, the fracture in the driveshaft leads to the catastrophic failure as it is connected to the live axles of the vehicle. So, it is necessary to design a driveshaft which is capable of transmitting the motion of engine to the rear wheels.

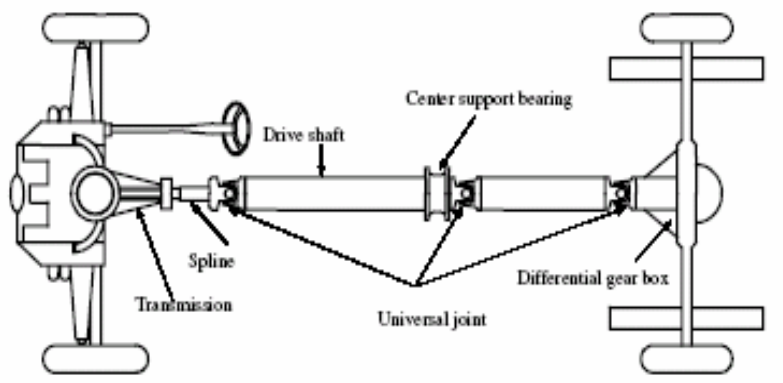

Fig.1Layout of transmission system

\section{Composite Driveshaft}

The conventional drive shafts consist of three universal joints, a center support bearing and bracket due to which weight of the shaft increases and affects fuel 
efficiency. The conventional drive shafts are made of stainless steel whereas the composite drive shaft is made of carbon or glass fiber epoxy resin material which is light in weight. The composite drive shaft has a higher specific rigidity, a higher specific strength, a higher resonance frequency and a higher vibration damping capability (Worgan, Derek, 1976) compared to the conventional metal drive shafts. The composite drive shaft is produced using the fiber-reinforced composite material eliminates the need for the universal joint, so that the drive shaft can be even lighter and generates less noise and resist the working moment (Choong, 2011). Thus, in advanced countries, such fiber-reinforced composite drive shafts are preferably used in special applications, such as in racing cars or aircraft.

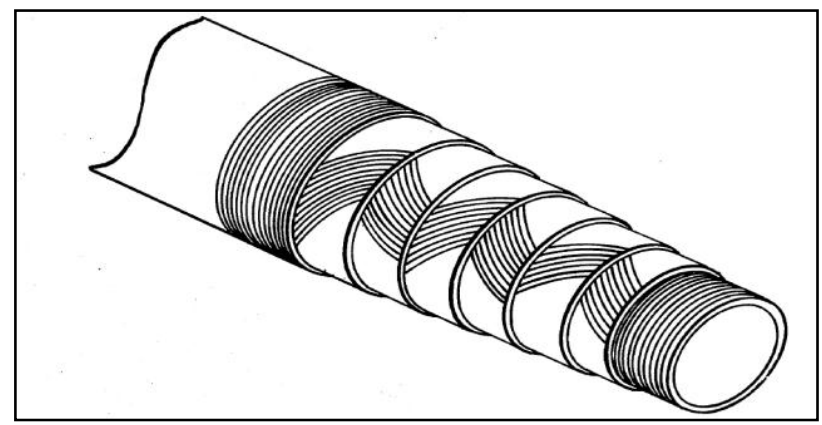

Fig.2Composite shaft

The hybrid composite drive shafts are also manufactured with the help of aluminum composite material in which the composite material was co-cured inside aluminum tube (Dai Gil Lee, et al., 2004). There are different methods of manufacturing the automotive composite driveshaft. These methods of the manufacturing are autoclave molding, vacuum bag pressure molding, filament winding etc. (Elmarakabi , 2014).

\section{Design of Composite Driveshaft}

\section{Specification of the Problem}

The torque transmission capability of the driveshaft should be larger than the $3,500 \mathrm{Nm}$ and the fundamental natural bending frequency of the passenger cars should be more than the $80 \mathrm{~Hz}$ i.e.it should be more than the minimum natural bending frequency. The outer diameter of the driveshaft should be such that it should not exceed $100 \mathrm{~mm}$ due to space limitation. Here, the outer diameter of the shaft is taken as $50 \mathrm{~mm}$. The driveshaft is to be design for the Maruti-Suzuki Omni vehicle.

\section{Assumptions}

1. About longitudinal axis, the shaft rotates at a constant speed.

2. The shaft has a circular and the uniform cross section along the length.
3. The shaft is such that at every cross section, the mass center coincides with the geometric center due to which the shaft is perfectly balanced.

4. All the non-linear and the damping effects are excluded.

5. The shaft is be made of composite material and Hooke's law is applicable for composite material i.e. the stress strain relationship for composite material is linear and elastic.

6. The shaft is considered as it is under plane stress as the lamina is thin and out-of-plane loads are applied.

\section{Selection of Cross-Section for the driveshaft}

For the selection of cross section of the drive shaft solid circular or hollow circular are generally considered. Here hollow circular cross section is chosen due to following advantages.

1. The solid circular shafts are weaker in per kg weight than the hollow circular shaft.

2. In case of the solid circular shaft, the stress distribution at the outer surface is more and at center it is zero. But in hollow circular shaft, stress variation is smaller

3. Also in solid circular shafts, material closer to the center is not fully utilized.

Selection of Reinforcement Fiber for the driveshaft (Rastogi, N., 2004, AutarK. Kaw ,2013)

The different types of fibers have different properties The fibers like carbon fiber, glass fiber and Kevlar fiber are commonly used for the composite driveshaft manufacturing. The selection of fiber for design of shaft depends on the physical properties and performance requirements.

Table 1 : Mechanical Properties of Fibers

\begin{tabular}{|c|c|c|c|c|c|c|}
\hline Material & $\begin{array}{c}\mathrm{E} \\
(\mathrm{GPa})\end{array}$ & $\begin{array}{c}\mathrm{G} \\
(\mathrm{GPa})\end{array}$ & $\gamma$ & $\begin{array}{c}\mathrm{S}_{\mathrm{ut}} \\
(\mathrm{MPa})\end{array}$ & $\begin{array}{c}\alpha \\
(\%)\end{array}$ & $\begin{array}{c}\rho \\
\left(\mathrm{Kg} / \mathrm{m}^{3}\right)\end{array}$ \\
\hline $\begin{array}{c}\text { Carbon } \\
\text { fiber HM }\end{array}$ & 385 & 20 & 0.23 & 3630 & 0.4 & 2170 \\
\hline $\begin{array}{c}\text { E-Glass } \\
\text { fiber }\end{array}$ & 72 & 27.7 & 0.3 & 3450 & 4.7 & 2580 \\
\hline $\begin{array}{c}\text { S-Glass } \\
\text { fiber }\end{array}$ & 87 & 33.5 & 0.3 & 4710 & 5.6 & 2460 \\
\hline $\begin{array}{c}\text { Kevlar 49 } \\
\text { fiber }\end{array}$ & 124 & 5 & 0.3 & 3850 & 2.8 & 1440 \\
\hline Steel & 206 & 81 & 0.27 & 648 & 4 & 7800 \\
\hline
\end{tabular}

Here, carbon fiber is selected due to its strength, modulus of rigidity and other mechanical properties.

\section{Selection of the resin system}

(Rastogi, 2004, AutarK. Kaw, 2013),The mixture or formulation of the polymer and polymer precursor material with various additives or chemically reactive components is known as the Resin. The processing, fabrication and the ultimate properties of composite material will affect the chemical composition and 
physical properties of the resin. The handling ability and processing ability of the composites may be affected by the variation in the composition, physical state or morphology of a resin and presence of impurities or contaminants in a resin.

Also, it affects the long term durability of the composite material and the properties of lamina/laminate.

Table 2: Mechanical properties of resins

\begin{tabular}{|c|c|c|c|c|c|c|}
\hline Material & $\begin{array}{c}\mathrm{E} \\
(\mathrm{GPa})\end{array}$ & $\begin{array}{c}\mathrm{G} \\
(\mathrm{GPa})\end{array}$ & $\gamma$ & $\begin{array}{c}\mathrm{S}_{\mathrm{ut}} \\
(\mathrm{MPa})\end{array}$ & $\begin{array}{c}\alpha \\
(\%)\end{array}$ & $\begin{array}{c}\rho \\
\left(\mathrm{Kg} / \mathrm{m}^{3}\right)\end{array}$ \\
\hline Epoxy & 3.1 & 1.2 & 0.3 & 70 & 4.0 & 1200 \\
\hline Polyester & 3.5 & 1.4 & 0.3 & 70 & 5.0 & 1100 \\
\hline $\begin{array}{c}\text { Resin } \\
\text { RTM 6 }\end{array}$ & 2.8 & 1.0 & 0.34 & 75 & 3.4 & 1140 \\
\hline $\begin{array}{c}\text { Resin } \\
\text { RTM120 }\end{array}$ & 2.6 & 0.9 & 0.35 & 77 & - & 1200 \\
\hline
\end{tabular}

The main factors considered in the selecting resin are mechanical properties and also resistance to impact (a function of modulus of elongation), elongation to failure, temperature capability and the important one is cost of the resin. The commonly used resins for the composite driveshaft are either epoxies or the vinyl esters. Here, epoxy resin is selected due to its strength, good wetting of fibers and lower curing shrinkage.

\section{Factor of Safety}

The important factor while designing a structure is factor of safety and it must be taken into account while designing. As the composites are orthotropic in nature and the fractures occur in composite material, the factor of safety for the composite driveshaft is taken as 6.

\section{Design considerations}

While designing a composite driveshaft, the important aspects which are needed to be considered based on the (Worgan\& Derek, 1976) and available standards of automotive driveshaft are as follows. Here, the composite driveshaft is designed for the specific application of passenger cars. The selected model of the passenger car is Maruti Suzuki Omni vehicle.

1. The thickness of the driveshaft is assumed to be 5 $\mathrm{mm}$.

2. The Length of the driveshaft is $0.66 \mathrm{~m}$.

3 . The outer diameter of the driveshaft of the vehicle is $50 \mathrm{~mm}$.

4. The shaft needs to withstand the Torsional buckling $\left(\mathrm{T}_{\mathrm{b}}\right.$ ) such that $\mathrm{T}_{\mathrm{b}}>\mathrm{T}$.

5. The minimum bending natural frequency of the driveshaft is $80 \mathrm{~Hz}$.

6. The maximum torque transmission capacity of the driveshaft in passenger cars is $3500 \mathrm{Nm}$.

Here, 60\% fiber volume fraction Carbon/Epoxy shaft $\left(\mathrm{V}_{\mathrm{f}}=60 \%\right)$ with standard ply thickness of $0.125 \mathrm{~mm}$ is selected.
Therefore, the total number of layers will be,

$$
\begin{gathered}
n=\frac{\text { thickness of the shaft }}{\text { ply thickness }} \\
n=40 \text { layers }
\end{gathered}
$$

\section{Torsional Strength}

The maximum shear stress of the shaft will be calculated by,

$$
\tau_{\max }=\frac{T}{2 \pi r_{m}^{2} t}
$$

where,

$r_{m}$ is the mean radius of the shaft.

Thus, the mean radius of the shaft will be calculated by,

$$
\begin{gathered}
r_{m}=r_{o}-\frac{t}{2} \\
r_{m}=22.5 \mathrm{~mm}
\end{gathered}
$$

Therefore, putting this value in shear stress equation, we get,

$$
\begin{gathered}
\tau_{\max }=\frac{T}{2 \pi r_{m}^{2} t} \\
\tau_{\text {max }}=220.06 \mathrm{~N} / \mathrm{mm}^{2}
\end{gathered}
$$

The torsional strength of the shaft is $220.06 \mathrm{~N} / \mathrm{mm}^{2}$

\section{Torsional buckling strength}

Considering the hollow composite shaft as anisotropic cylindrical shell, the buckling torque is given by:

$$
T_{b}=2 \pi r^{2} t \times 0.272 \times\left(E_{x} \times E_{y}^{3}\right)^{\frac{1}{4}} \times\left(\frac{t}{r}\right)^{\frac{3}{2}}
$$

where,

$\mathrm{E}_{\mathrm{x}}=$ Young's modulus in ' $\mathrm{x}$ ' direction

$E_{y}=$ Young's modulus in ' $y$ ' direction

Here, we considered the composite driveshaft as orthotropic lamina. So, for orthotropic lamina, the longitudinal elastic modulus will be calculated by following formula,

$$
\begin{aligned}
\frac{1}{E_{x}}=\frac{1}{E_{1}} \times(\cos \theta)^{4} & +\left(\frac{1}{G_{12}}-\frac{2 \vartheta_{12}}{E_{1}}\right) \times(\sin \theta)^{2}(\cos \theta)^{2} \\
& +\frac{1}{E_{2}}(\sin \theta)^{4} \\
\frac{1}{E_{y}}=\frac{1}{E_{1}} \times(\sin \theta)^{4} & +\left(\frac{1}{G_{12}}-\frac{2 \vartheta_{12}}{E_{1}}\right) \times(\sin \theta)^{2}(\cos \theta)^{2} \\
& +\frac{1}{E_{2}}(\cos \theta)^{4}
\end{aligned}
$$

The values of $E_{x}$ and $E_{y}$ will be found out with the help of $E_{1}, E_{2}, G_{12} \& \vartheta_{12}$ values.

The value of $\theta$ i.e. Stacking sequence angle will be taken so that the torsional buckling strength will be more than that of the maximum torque applied.

Here, the stacking sequence angle is taken as $45^{\circ}$ as it resist pure torsion. The stacking sequence is as follows.

$[ \pm 45 / \pm 45 / \pm 45 / \pm 45 / \pm 45]$ 2s 
The values of $E_{1}, E_{2}, G_{12} \& \vartheta_{12}$ will be taken from table of properties of fiber/epoxy plies which is for unidirectional lamina.

Putting the values of $E_{1}, E_{2}, G_{12} \& \vartheta_{12}$ from above table in equation (2) and equation (3), we get the values of $E_{x}$ and $E_{y}$.

$\frac{1}{E_{X}}=\frac{1}{E_{1}} \times(\cos \theta)^{4}+\left(\frac{1}{G_{12}}-\frac{2 \vartheta_{12}}{E_{1}}\right) \times(\sin \theta)^{2}(\cos \theta)^{2}+$

$\frac{1}{E_{2}}(\sin \theta)^{4}$

$\frac{1}{E_{x}}=9.61 \times 10^{-5}$

$E_{x}=10398.15 \mathrm{MPa}$

The value of $E_{x}$ is $10398.15 \mathrm{MPa}$.

Now, putting the values in equation (3), we get,

$\frac{1}{E_{y}}=\frac{1}{E_{1}} \times(\sin \theta)^{4}+\left(\frac{1}{G_{12}}-\frac{2 \vartheta_{12}}{E_{1}}\right) \times(\sin \theta)^{2}(\cos \theta)^{2}$ $+\frac{1}{E_{2}}(\cos \theta)^{4}$

$\frac{1}{E_{y}}=8.77 \times 10^{-5}$

$E_{y}=11392 \mathrm{MPa}$

The value of $E_{y}$ is $11392 \mathrm{MPa}$

Substituting above values, we get

$T_{b}=5046060.78 \mathrm{Nmm}$

Here, $T_{b}>T$

$$
T_{b}=5046.06 \mathrm{Nm}
$$

Therefore, the design is safe.

\section{Natural frequency}

(Leslie, et al.,1996)The bending natural frequency of the shaft is given by,

$$
f_{n_{b}}=\frac{\pi}{2} \sqrt{\frac{E_{x} I_{x}}{m^{\prime} L^{4}}}
$$

Here,

The moment of inertia of hollow shaft is given by,

$$
\begin{gathered}
I_{x}=\frac{\pi}{64}\left(d_{o}^{4}-d_{i}^{4}\right) \\
I_{x}=0.18 \times 10^{-6} m^{4}
\end{gathered}
$$

The mass per unit length of the shaft is given by,

Hence,

$$
\begin{gathered}
m^{\prime}=\rho \frac{\pi}{4}\left(d_{o}^{2}-d_{i}^{2}\right) \\
m^{\prime}=1.08 \mathrm{~kg} / \mathrm{m}
\end{gathered}
$$

$I_{x}=0.18 \times 10^{-6} \mathrm{~m}^{4}$

and $m^{\prime}=1.08 \mathrm{~kg} / \mathrm{m}$.

Upon substitution, the fundamental bending natural frequency is,

$$
\begin{gathered}
f_{n_{b}}=\frac{\pi}{2} \sqrt{\frac{E_{x} I_{x}}{m^{\prime} L^{4}}} \\
f_{n_{b}}=150.47 \mathrm{~Hz}(>80 \mathrm{~Hz})
\end{gathered}
$$

Here, the fundamental bending natural frequency of composite shaft is greater than the minimum natural frequency of the composite shaft assumed.

Therefore, the designed composite shaft is safe.
Critical Speed of the Composite Shaft (Duggan, et al., 1993),

The critical speed of the shaft is given by,

$$
\begin{aligned}
& \text { Critical speed }=\frac{654.8 \times D}{L^{2}} \sqrt{\frac{E}{\rho}} \\
& \therefore \text { Critical speed }=8132 \mathrm{rpm}
\end{aligned}
$$

Therefore, the critical speed of the shaft is $8132 \mathrm{rpm}$ which is more than the maximum speed of the transmission system.

\section{Results}

The values of torsional strength, torsional buckling strength, fundamental bending natural frequency and the critical speed of the composite shaft are calculated and are as follows.

Table 3 Values of the designed carbon/epoxy composite shaft

\begin{tabular}{|c|c|}
\hline Parameters & Values \\
\hline Torsional strength & $220.06 \mathrm{~N} / \mathrm{mm}^{2}$ \\
\hline Torsional buckling strength & $5046.06 \mathrm{Nm}$ \\
\hline $\begin{array}{c}\text { Fundamental bending natural } \\
\text { frequency }\end{array}$ & $150.47 \mathrm{~Hz}$ \\
\hline Critical speed & $8132 \mathrm{rpm}$ \\
\hline
\end{tabular}

\section{Conclusions}

The designed composite drive shaft for passenger car has much less weight as compared to the steel shaft The composite shaft consists of carbon epoxy material and has weight $0.7 \mathrm{~kg}$. The fundamental natural bending frequency of composite shaft is $150 \mathrm{~Hz}$. The critical speed of the composite shaft is $8132 \mathrm{rpm}$. The values of fundamental natural bending frequency and critical speed of composite drive shaft are higher than the steel drive shaft. As the bending natural frequency of the composite shaft is more, the vibration of the system reduces. Also as the critical speed i.e.8132 rpm is more than the maximum speed of the engine i.e. $5700 \mathrm{rpm}$, the whirling of the shaft is avoided. The weight of the steel shaft is $3.6 \mathrm{~kg}$ and the weight of the composite shaft is $0.7 \mathrm{~kg}$ i.e. the amount of energy required to propel the vehicle is reduces and thereby the fuel consumption is reduced.

\section{Nomenclature}

$\begin{array}{cl}T_{\max } & \text { Maximum torque } \\ N_{\max } & \text { Maximum speed } \\ \mathrm{L} & \text { Length of the shaft } \\ n & \text { Number of layers } \\ r_{m} & \text { Mean radius of the composite shaft } \\ r_{o} & \text { Outer radius of the composite shaft }\end{array}$


$r_{i} \quad$ Inner radius of the composite shaft

$\tau_{\max } \quad$ Shear Stress

$\tau_{b} \quad$ Buckling torque

$E_{x} \quad$ Young's modulus in 'x' direction

$E_{y} \quad$ Young's modulus in 'y' direction

$t \quad$ Thickness of the composite shaft

$\theta \quad$ Stacking sequence angle

$E_{1} \quad$ Longitudinal elastic modulus

$E_{2} \quad$ Transverse elastic modulus

$G_{12} \quad$ Modulus of rigidity

$\vartheta_{12} \quad$ Poisson's ratio

$\rho \quad$ Density

$f_{n_{b}} \quad$ Bending natural frequency

$I_{x} \quad$ Moment of inertia

$m^{\prime} \quad$ Mass per unit length

$g \quad$ Acceleration due to gravity

I Area moment of inertia

A Area

E Young's modulus

G Shear modulus

$\gamma \quad$ Axial poisson's ratio

$\mathrm{S}_{\mathrm{ut}} \quad$ Ultimate strength (MPa) tension

$\alpha \quad$ Strain to failure (\%)

\section{References}

Reimpell J, Stroll H. (1996),The automotive chassis: Engineering principles, New York: Society of Automotive Engineers.

Dai Gil Lee, hak Sung Kim, Jong Woon Kim, Jin Kook Kim(2004),Design and manufacture of an automotive hybrid aluminum/composite driveshaft, ELSEVIER, Composite structures 63, pp.87-99.

Gordon Peter Worgan, Derek Reginald Smith(1976), Carbon fiber drive shaft, Patent publication number- US 4089190.

Xu Fang-Jing, Ye Jian-Rong and Xue Yuan-DE, (1991),Design and Mechanical Analysis of a Hybrid Composite Driveshaft,ELSEVIER, Composite Structures.

Choong o Ryu(2011),Method of manufacturing a composite drive shaft manufactured using mold, Patent publication number- US 8459978 B2.

Ahmed Elmarakabi (2014), Advanced Composite Materials for Automotive Applications, Wiley publications, p.p. 8-9.

Composite Materials Handbook, Department of Defense Handbook, Volume 3. Polymer Matrix Composites Materials Usage, Design and Analysis, MIL-HDBK-17-3e,23 January 1997,pp-2.1-2.31.
Rastogi, N.(2004),Design of Composite Driveshafts for Automotive Applications,SAE Technical Paper 2004-01-0485, doi: 10.4271 /2004-01-0485.

AutarK. Kaw (2013),Mechanics of Composite Materials, Taylor and Francis group, CRC press, pp.-411-420.

Robert Jones(2011), Mechanics of composite material,CRC press, pp. 81-83.

Daniel Gay(2003), Composite materials: Design and Applications, CRC Press, pp.-39-42.

Leslie J.C., Truong L., Leslie J.C. II and Bruce Blank (1996),Composite Driveshafts: Technology and Experience, Society of Automotive Engineers, 962209.

Abrate, S.(1989), Composite Driveshaft Designs, SAE Technical Paper 891031, doi:10.4271/891031.

Byerly, D.(1996),The Use of Continuous Fiber Composites in Driveshafts, SAE Technical Paper, doi:10.4271/962208.

Duggan, J., Dickson, J., and Hoover, W.(1993), Aluminum Composite Driveshafts,SAE Technical Paper, doi: 10.4271/933054.

Moorthy R.S., Mitiku Y.\& Sridhar K. (2014), Design of Automobile Driveshaft using Carbon/Epoxy and Kevlar/Epoxy Composites, American Journal of Engineering Research,02, pp-173-179.

Abu Talib A. R., Ali Adity, Badie Mohamed A. , CheLahNurAzida Golestaneh A.F.(2010),Developing a hybrid, carbon/glass fiber reinforced epoxy composite automotive drive shaft, ELSEVIER Material and design 31, pp.514-521. ChristophRoos, Bakis Charles E., (2011), Multi physics design and optimization of flexible matrix composite driveshaft, ELSEVIER, Composite structures 93, pp.22312240.

Montagnier O., Hochard Ch., (2013), Optimization of hybrid high modulus/high strength carbon fiber reinforced plastic composite drive shaft, ELSEVIER, Material and Design 46, pp. 88-100.

Alksandr Cherniaev ,Valeriy Komarov(2014), Multistep optimization of composite drive shaft subject to strength, buckling, vibration and manufacturing constraints, SPRINGER, Application of Composite Material, DOI 10.1007/s10443-014-9418-z.

Gubran H.B.H. , Gupta K. (2005), The effect of stacking sequence and coupling mechanisms on the natural frequencies of composite shafts, ELSEVIER, Journal of Sound and Vibration 282, pp.231-248.

Mutasher S.A. (2009), Prediction of the torsional strength of the hybrid aluminum/composite drive shaft,ELSEVIER, Materials and Design 30, pp.215-220.

Henry Todd C., Bakis Charles E. , Miller Simon W. , Smith Edward C. (2015), Multi-objective optimal design of composite rotorcraft driveshaft including strain rate and temperature effects, ELSEVIER, Composite structures 128, pp.42-53.

Ummuhaani A. M. , Sadagopan P. (2011), Design, Fabrication and Stress Analysis of a Composite Propeller Shaft, SAE International, DOI: $10.4271 / 2011-28-0013$.

Theocaris Pericles S. , Stavroulakisb G. E. \& Panagiotopoulos P. D. (1996),Calculation of effective transverse elastic Moduli of fiberreinforced composites by Numerical homogenization,ELSEVIER,Composites Science and Technology, pp. 573-586.

Khalid Y.A. , Mutasher S.A. , Sahari B.B. , Hamouda A.M.S. , (2005), Bending fatigue behavior of hybrid aluminum/composite drive shafts, ELSEVIER, Materials and Design 28, pp.329-334.

ErcanSevkat, HikmetTumer, M. HalidunKelestemur, SelimDogan (2014), Effect of torsional strain-rate and lay-up sequences on the performance of hybrid composite shafts, ELSEVIER, Materials and Design 60, pp. 310-319.

Shokrieh Mahmood M., Hasani A., Lessard Larry B. (2004), Shear buckling of a composite drive shaft under torsion, ELSEVIER, Composite Structures 64, pp. 63-69.

Kim Hak Sung , Lee Dai Gil , (2004), Optimal design of the press fit joint for a hybrid aluminum/composite drive shaft, ELSEVIER, Composite Structures 70, pp.33-47.

Badie M.A., Mahdi E., Hamouda A.M.S. (2011), An investigation into hybrid carbon/glass fiber reinforced epoxy composite automotive drive shaft,ELSEVIER, Materials and Design 32 , pp.1485-1500. 